\title{
Use of a Portable Microscope Combined with a Smartphone to Determine the Authenticity of Brazilian Banknotes and National Driver's Licenses
}

\author{
Rayana A. Costa, ${ }^{a, b}$ Bruno V. Vittorazzi, ${ }^{c}$ Amanda P. Barbosa, ${ }^{b}$ Victória B. da Rocha, ${ }^{b}$ \\ Jandira M. O. B. Brandão, ${ }^{d}$ Valdemar Lacerda Jr., ${ }^{\oplus *, a}$ Paulo R. Filgueiras ${ }^{\circledR a}$ and \\ Wanderson Romão ${ }^{\circledR} *, a, b, e$ \\ ${ }^{a}$ Laboratório de Petroleômica e Química Forense, Departamento de Química, \\ Universidade Federal do Espírito, 29075-910 Vitória-ES, Brazil \\ ${ }^{b}$ Instituto Federal do Espírito Santo, 29150-410 Cariacica-ES, Brazil \\ 'Instituto Federal do Espírito Santo, 29106-010 Vila Velha-ES, Brazil \\ ${ }^{d}$ Laboratório de Documentoscopia da Polícia Técnico-Científica da Polícia Civil do Estado do Espírito Santo, \\ 29045-300 Vitória-ES, Brazil \\ eInstituto Nacional de Ciência e Tecnologia Forense (INCT Forense), 29106-010 Vila Velha-ES, Brazil
}

\begin{abstract}
This study proposed using a portable microscope combined with a smartphone and application (PhotoMetrix ${ }^{\circledR}$ application) to evaluate the authenticity of Brazilian banknotes ( $\mathrm{R} \$ 50$ and $\mathrm{R} \$ 100$ ) and national driver's licenses (NDL) through image acquisition (Samsung S7) and chemometric treatment (principal component analysis (PCA)). Six regions of the banknote were analyzed: holographic band; lower and upper tactile regions containing the number referring to the value of the note; microprints above the effigy (obverse); and numbers and the surroundings of the animal formed by microprints (reverse). For NDLs, the regions were the following: the coat of arms of the republic; the state map with microprints; optical ink variation; distorted positive microletters with technical failure; negative guilloche; typographic numbering; micro letter wire; and region with line printing. For the chemometric study with Photometrix ${ }^{\circledR}$, we selected a region of interest (ROI) of $32 \times 32$ and $64 \times 64$ pixels with autoscaled data using the channels red $(\mathrm{R})$, green $(\mathrm{G})$, blue (B), hue (H), saturation (S), value (V), lightness (L) and intensity (I). We obtained excellent results for differentiating banknotes and NDLs, both by visual and chemometric analyses (PCA). This study demonstrates the effectiveness of using a portable microscope and a smartphone as a portable forensic tool that is fast, robust, low-cost and reliable.
\end{abstract}

Keywords: documents, microscope, smartphone, digital image, PCA

\section{Introduction}

Falsification of documents impacts the development of the economy, since it promotes the development of crime in several countries. ${ }^{1,2}$ In the field of forensic chemistry, document analysis has become a prominent method since documentoscopy can be used to determine the authenticity of a document by examining it and comparing it to other documents. ${ }^{3-5}$ While several types of documents can be forged or adulterated, including a national driver's license, identity card and individual registration, the adulteration of banknotes is considered to be the largest financial crime and

*e-mail: vljuniorqui@gmail.com; wandersonromao@gmail.com Editors handled this article: Eduardo Carasek and Ivo M. Raimundo Jr. (Associate) requires high levels of sophistication. In 2019, according to Central Bank of Brazil (CBB), 492,193 banknotes were falsified, which were seized mainly in the states of São Paulo, Rio de Janeiro and Minas Gerais. ${ }^{6}$ In addition, 75,501 counterfeit banknotes were produced from January to March $2020 .^{7}$

To minimize counterfeiting, in 2010 the CBB presented new security items with advanced features for the second generation of the Real banknote, including microprints, holographic bands, puzzles and fluorescent elements. ${ }^{8}$ Despite the CBB's efforts, counterfeit activities continue to grow; the highest values of Brazilian banknotes ( $\mathrm{R} \$ 100$ and $\mathrm{R} \$ 50)$ are the main targets, totaling 271,453 counterfeits in 2019 and comprising $55 \%$ of the total seizure. ${ }^{6}$ 
To verify the authenticity of documents, a visual analysis is first performed followed by more detailed analytical examinations, ${ }^{2}$ such as video spectral comparator (VSC), Raman spectroscopy, ${ }^{9,10}$ thin layer chromatography (TLC), ${ }^{11} \mathrm{X}$-ray fluorescence, ${ }^{12}$ capillary electrophoresis, ${ }^{13}$ mass spectrometry (MS), ${ }^{14-16}$ portable near-infrared spectroscopy ${ }^{1,17}$ and terahertz spectroscopy. ${ }^{18}$ However, some of these techniques, mainly TLC, require a sample preparation step, which can potentially destroy material evidence. During the investigative process, the preservation of the material is critically important. ${ }^{4}$ Thus, in Brazil, the forensic laboratory uses the VSC technique, which uses images reproduced by reflectance spectrophotometry that can be viewed in the ultra-violet (UV), visible (Vis) or infrared (IR) ranges. This approach is used widely since it allows for visualizing the safety items developed by CBB. ${ }^{2}$

The use of simple and low-cost analyses in scientific settings has been growing due to recent technological advances such as the use of portable equipment for analyzing digital images, ${ }^{19-23}$ which have been shown to be fast, non-destructible and reliable for specific forensic applications. ${ }^{1}$ In this context, a portable microscope was combined with a smartphone (equipped with the PhotoMetrix ${ }^{\circledR}$ application) to investigate the authenticity of Brazilian banknotes ( $\mathrm{R} \$ 50$ and $\mathrm{R} \$ 100)$ and national driver's licenses (NDLs).

\section{Experimental}

\section{Samples}

Ten authentic NDLs were used for this study. Counterfeit NDLs $(n=30)$ were obtained through homemade printing, i.e., wax (Xerox ColorQube $8880^{\circledR}$ ), deskjet (Epson L656 ${ }^{\circledR}$ ) and laserjet (Konica Minolta $654^{\circledR}$ ) printers used to scan authentic NDLs.

For the experiment, $\mathrm{n}=51 \mathrm{R} \$ 50$ banknotes were used. Of these, $n=30$ authentic banknotes, $n=9$ counterfeit banknotes (seized by the Civil Police of the state of Espírito Santo) and $\mathrm{n}=12$ simulated banknotes (obtained through digital image of banknotes made available by CBB) printed by wax, deskjet and laserjet. The number of banknotes of $\mathrm{R} \$ 100$ was $n=49$, differing only the quantity of counterfeit banknotes seized by the police with $n=7$. Authentic banknotes were obtained from local bank branches.

\section{Data analysis}

We used a universal microscope for smartphones (Figure 1) to obtain images of the $\mathrm{R} \$ 50$ and $\mathrm{R} \$ 100$ banknotes and NDLs. Initially, we acquired images using the magnifying glass in obverse and reverse regions of the banknotes: the holographic range (a), the tactile region of the lower left number (b), the microprinting in the effigy region (c), the tactile region of the upper right number (d), the microprinting of the left number (e) and the region surrounding the animals (jaguar and grouper) (f) (Figure 2A). For NDLs, we used images of regions: (a) the coat of arms of the republic in calcography, (b) the map of the state with microprinting of the acronym, (c) optical variation ink, (d) distorted positive micro letters with technical failure, (e) negative guilloche with imaging, (f) typographic numbering, (g) wire of positive micro letters, and (h) a region with line printing (Figure 2B).

To carry out an exploratory analysis of the results, a principal component analysis (PCA) and a hierarchical

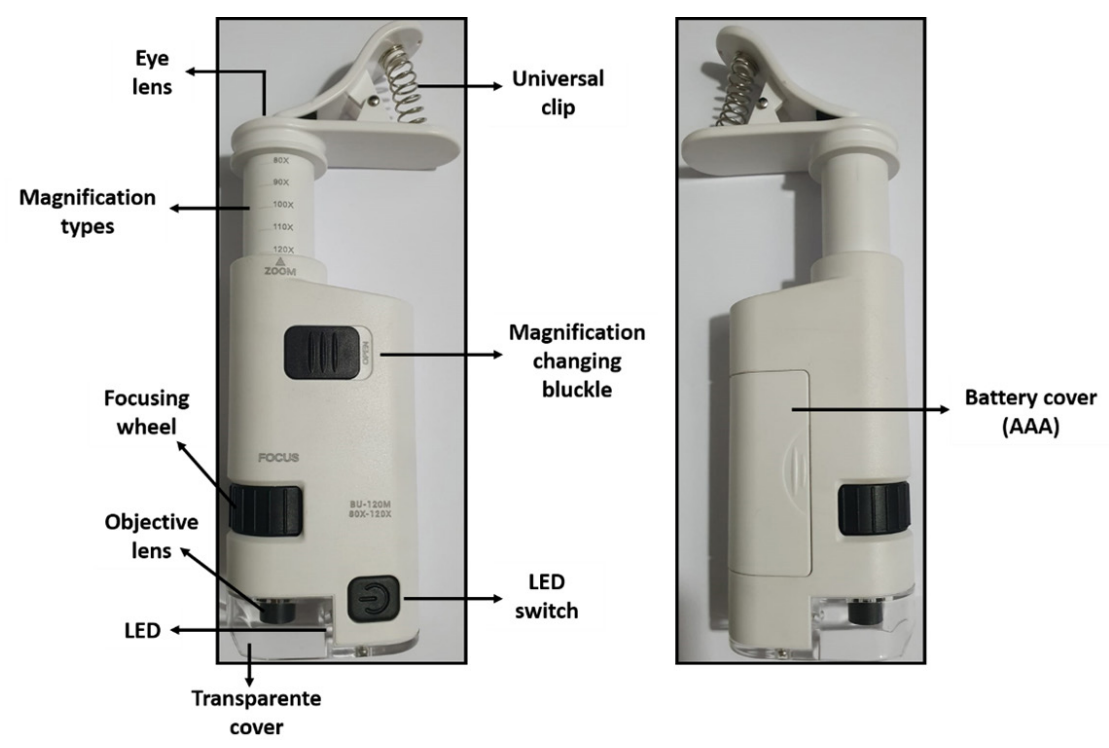

Figure 1. Representation of a universal, portable microscope for smartphone use; characteristics of the microscope are indicated with arrows. 


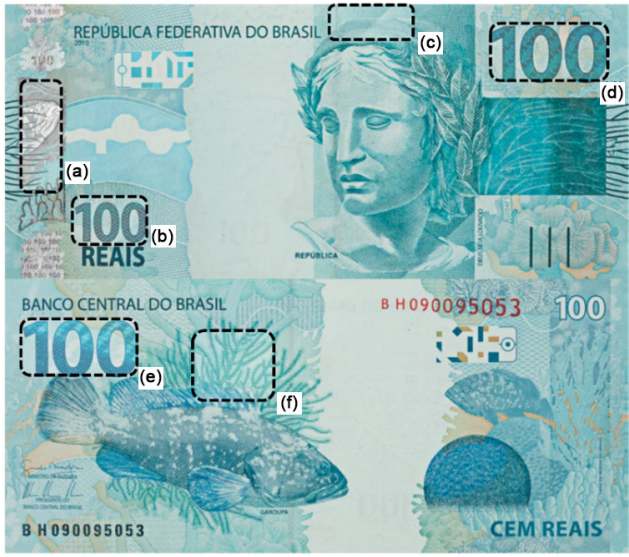

(A)

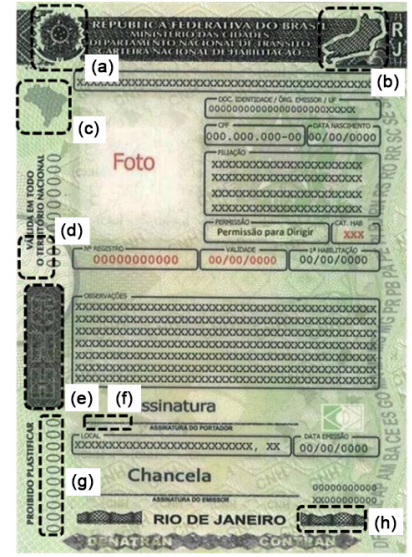

(B)

Figure 2. Regions of the R $\$ 100$ banknotes (A) and NDL (B) investigated in this study. On the $\mathrm{R} \$ 100$ banknote (A), these regions were the following: (a) the holographic band, (b) the tactile region of the lower left number, (c) the microprinting in the effigy region, (d) the tactile region of the upper right number, (e) the microprinting in the left number and (f) the region around the animal figures. On the NDL (B), the regions included (a) regions of the coat of arms of the republic in calcography, (b) a state map with microprinting of the acronym, (c) optical variation ink, (d) distorted positive micro letters with technical failure, (e) negative guilloche with imaging, (f) typographic numbering, (g) wire of positive micro letters, and (h) a region with line printing.

cluster analysis (HCA) were performed using the PhotoMetrix ${ }^{\circledast}$ application with the portable microscope and the images obtained with the smartphone (Samsung S7, android 9.0 pie, 12 megapixel camera, optical stabilization, $4290 \times 2800$ pixel resolution, and F 1.7 aperture). In the PCA, the data were autoscaled using the channels red (R), green $(\mathrm{G})$, blue $(\mathrm{B})$, hue $(\mathrm{H})$, saturation $(\mathrm{S})$, value $(\mathrm{V})$, lightness (L) and intensity (I), ${ }^{22,23}$ with a region of interest (ROI) of $64 \times 64$ and a magnification factor of $120 \times$. Using the intensity of the channels to compose the data matrix, we had a total of 2,048 variables/information, since each component generates an intensity of 256 values from the pre-processed data by autoscaling. After capturing the image, taking into consideration the region of interest used, an array was generated using the intensity of each channel, and the pixel number was calculated. For each ROI, the pixel number had an intensity from 0 to 255 , e.g., 256 values. Thus, PCA charts were generated that contained scores and loading plots from the Photometrix ${ }^{\circledR}$ application.

\section{Results and Discussion}

We observed some of the security elements cited by the CBB with very high resolution by using images of $\mathrm{R} \$ 50$ and $\mathrm{R} \$ 100$ banknotes and NDLs obtained with a portable microscope and a smartphone. Using these images (Figures 3A and 3D), it was possible to visually distinguish between authentic and counterfeit banknotes using the universal microscope for smartphone since the security elements (Figures 3A-3C) in the authentic documents were visibly well defined and contained characteristic information, according to the booklet of the second family of the Real currency written by the CBB.
The holographic band includes metallized parts. The word "REAL" (Figure 3Aa) or the value of the banknote ("50", Figure 3Da) is visible on the banknote; these indicators are not visualized in false banknotes because there are only blurs of a mixture of colors (Figures $3 \mathrm{Ba}, 3 \mathrm{Ca}, 3 \mathrm{Ea}$ and $3 \mathrm{Fa}$ ). The regions above the effigy (Figure $3 \mathrm{Ac}$ ), close to the puzzle (Figures $3 \mathrm{Ae}$ and $3 \mathrm{De}$ ), the banknote number (Figures $3 \mathrm{Ae}$ and $3 \mathrm{De}$ ) and the animal's surroundings (Figures 3Af and 3Df) have microprints on the value for each banknote. Using the universal microscope, this information was clearly different between the simulated and counterfeit banknotes (Figures 3B, 3C, 3E and 3F). Similarly, we compared the images using a widely disseminated method that employs VSC, which compares the security elements issued by the $\mathrm{CBB}$ with the banknotes seized as counterfeit. As shown in Figure S1, Supplementary Information (SI) section, using the VSC technique (VSC 6000, Foster \& Freeman, United Kingdom) to evaluate the counterfeit banknotes, the security elements contained in the holographic band (Figures 1a, 1b, 1d) and numbers referring to the value of the banknote (Figures 1c, 1e, 1f) are not displayed. The counterfeit banknotes seized (Figure S1) appeared visually similar to the authentic banknotes (Figures 3A and 3D). The lack of authenticity of the banknotes could have been indicated by the absence or rudimentary appearance of security elements typically contained in the analyzed regions. Thus, using tools to differentiate between authentic and counterfeit banknotes is extremely important. It is also important to highlight that a portable microscope equipped with a smartphone provides mobility and can perform on-site analysis by generating high resolution images in the expert routine. 

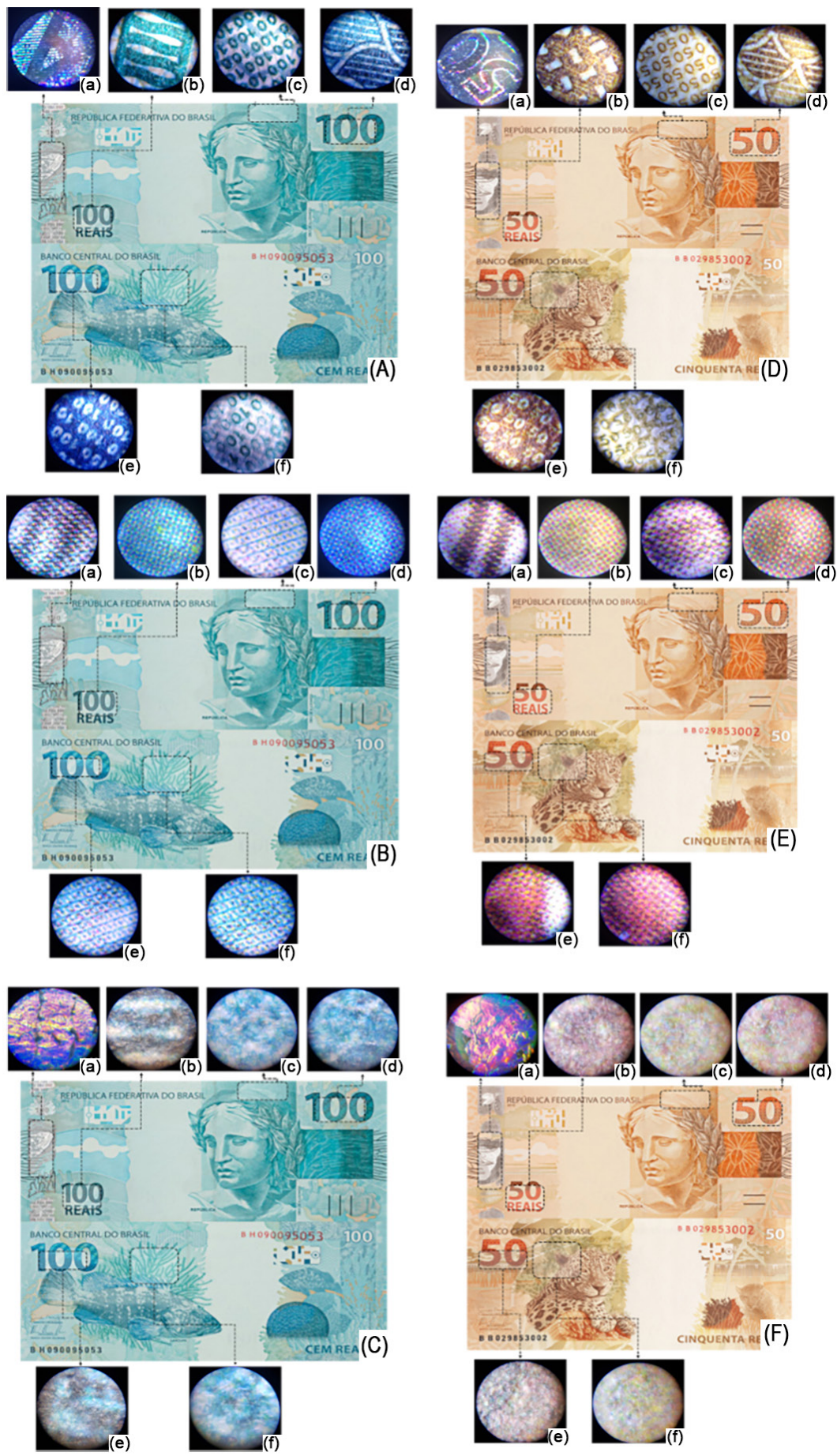

Figure 3. Authentic (A,D), simulated (B,E) and counterfeit (C,F) banknotes of $R \$ 100$ and $R \$ 50$ obtained through a smartphone used with a $120 \times$ magnifying glass. The regions studied were: (a) the holographic band, (b) the tactile region lower left number, (c) the microprinting effigy region, (d) the tactile region upper right number, (e) the microprinting left number and (f) the microprinting animal figure region.

For NDL, we visualized the characteristics that were similar to authentic banknotes; the hidden information in the authentic documents (Figure 4A) was clear and had a high resolution in the printing as "SES" (Figure 4Ab); "CAR" (Figure 4Ag) the coat of arms of the republic in calcography (Figure 4Aa) and trace crossing (Figure 4Ah). For counterfeit NDL samples made using homemade printers (wax, inkjet and laser), the elements were presented in blurry forms but with profiles and shades of different colors, as shown in Figures 4B, 4C and 4D.

To evaluate and differentiate the authenticity of the documents, we used a universal microscope coupled to a Samsung S7 smartphone to acquire images through the PhotoMetrix $^{\circledR}$ app. Three PCA models were implemented, 


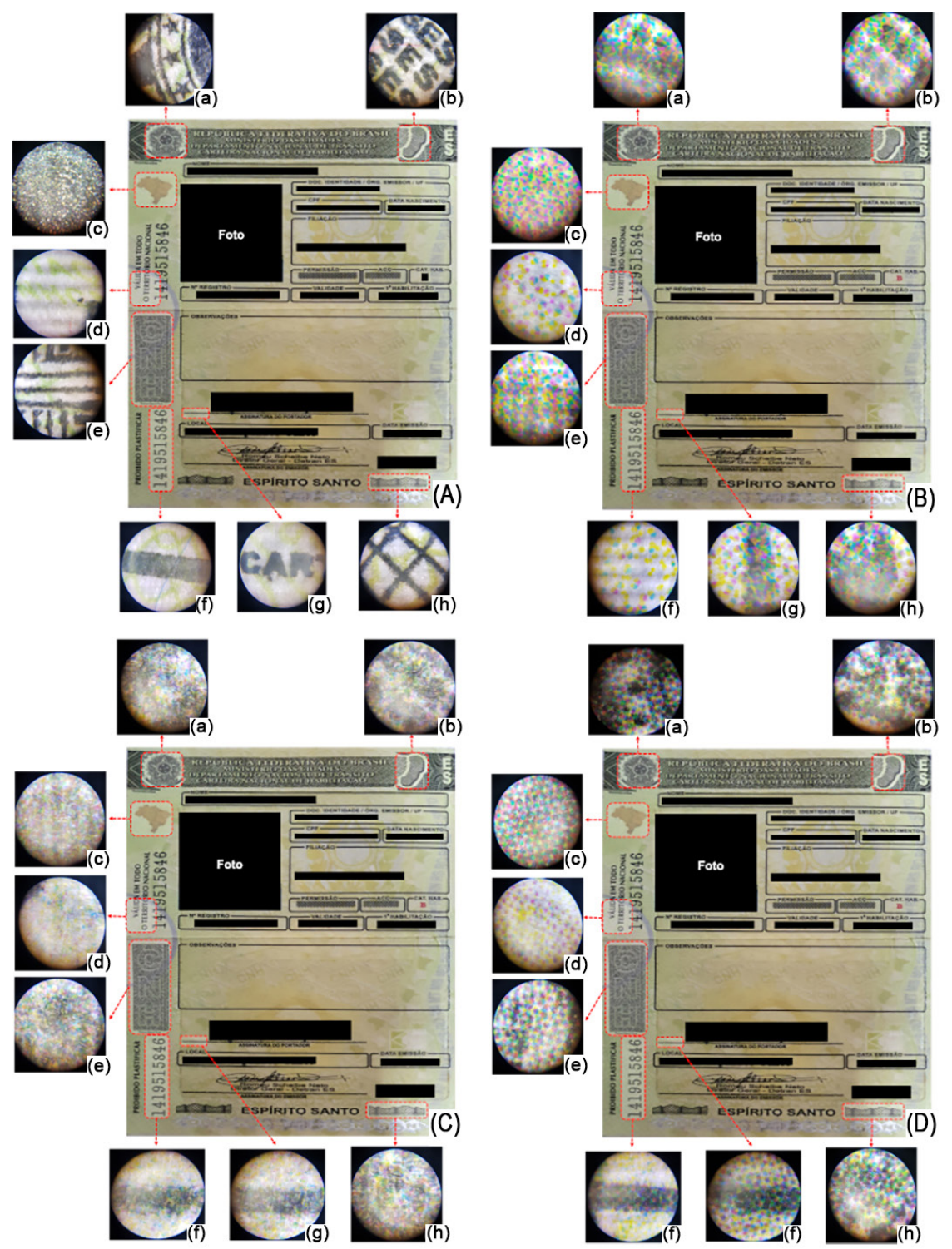

Figure 4. Authentic (A) and counterfeit NDL regions ((B) wax, (C) inkjet, (D) laser) obtained through smartphone camera equipped with a $120 \times$ magnifying lens. The NDL regions that were studied were: (a) the coat of arms of the republic in calcography, (b) the state map with the calcography acronym, (c) optical variation ink, (d) positive and distorted micro letters with technical failure, (e) negative guilloche with imaging, (f) typographic numbering, (g) wire of positive micro letters, and (h) a region with line printing.

one for each value of banknotes, $\mathrm{R} \$ 50$ (Figure $5 \mathrm{~b}$ ) and $\mathrm{R} \$ 100$ (Figure 5a), and one for NDLs (Figures 6a and 6b) based on the data obtained in Figures 3 and 4, respectively.

The PCA analysis was performed by evaluating the values of channels $\mathrm{R}, \mathrm{G}, \mathrm{B}, \mathrm{H}, \mathrm{S}, \mathrm{V}, \mathrm{L}$ and I with the autoscaled data and the ROI of $32 \times 32$ pixels. For all the regions analyzed in the $\mathrm{R} \$ 50, \mathrm{R} \$ 100$ and NDL, two regions were chosen for banknotes (region d, above the number referring to the banknote value (obverse) and region e, micro printing in the number (reverse)) and one region for NDLs (region b: map of the State of ES with the acronym in calcography (obverse)). Figures 5a-5f shows the scores and loadings plots (PC1 vs. PC2) for the $\mathrm{R} \$ 100$ and $\mathrm{R} \$ 50$ banknotes. The PCA score plot of the $\mathrm{R} \$ 100$ banknotes (Figure 5a), showed the formation of three groups: the first group corresponds to authentic banknotes, while the other two groups indicate false banknotes (wax, jet, laser and offset), separated into one group by offset (counterfeit banknote) and another by wax, laser and inkjet. For region e of the $\mathrm{R} \$ 100$ banknote, the $\mathrm{PC} 1 \times \mathrm{PC} 2$ score plot revealed that both PCs were able to significantly distinguish between the banknotes. The PC2 region was responsible for the spatial differentiation between the authentic (1-30) and counterfeit banknotes (43-49) seized by PC-ES. Well-defined groupings, the G, B, $\mathrm{S}, \mathrm{V}, \mathrm{L}$ and I channels, influenced the separation of authentic banknotes. For PC1 $<0$, it is observed the distinction of authentic and simulated banknotes (31-42; wax, laser and 
inkjet). For the $\mathrm{R} \$ 50$ banknote, we found region 4 to be the PC2 responsible for differentiating between authentic (1-30), simulated (31-42) and counterfeit banknotes (43-51). Evaluating the PC2 loadings plot (Figure 5d) showed that the R, G, S and V channels were responsible for discriminating authentic banknotes, while the $\mathrm{B}$ and $\mathrm{H}$ channels discriminated the counterfeit ones.

HCA is another widely used method for viewing existing clusters in space and involves evaluating the similarity between samples. Figure S2, SI section, shows the formation of three groups where the similarity between the authentic and counterfeit samples of a $\mathrm{R} \$ 100$ banknote can be identified by considering the complete linkage grouping method. This finding corroborates the PCA results in which the hue channel $(\mathrm{H})$ presented a higher PC2 value (grouping of counterfeit banknotes) and formed the grouping of counterfeit banknotes. Even both of them presenting offset printing, the difference is related to the type of ink used in the making of banknotes. Authentic banknotes are produced with organic pigments, additives and varnishes, while counterfeit banknotes are prepared by organic or inorganic pigments and additives. The copiers employ four colors (cyan, yellow, black and magenta) to achieve the same hue of the seventeen superimposed colors found in the manufacture of the Real banknote. Therefore, hue is a fundamental aspect for differentiating between banknote. A similar finding was observed for the $\mathrm{R} \$ 50$ banknotes, in which three groups were trained by similarity (Figure S3, SI section). We observed that difference in the sample group actually occurs with the formation of small branches. In addition, the longer trunk that unites the authentic and counterfeit groups indicates that they are located at a distance from each other, and the group of counterfeits was more compact.

Helfer et al. ${ }^{23}$ evaluated Real (R\$) and Argentine weight banknotes through digital images using the PhotoMetrix ${ }^{\circledR}$
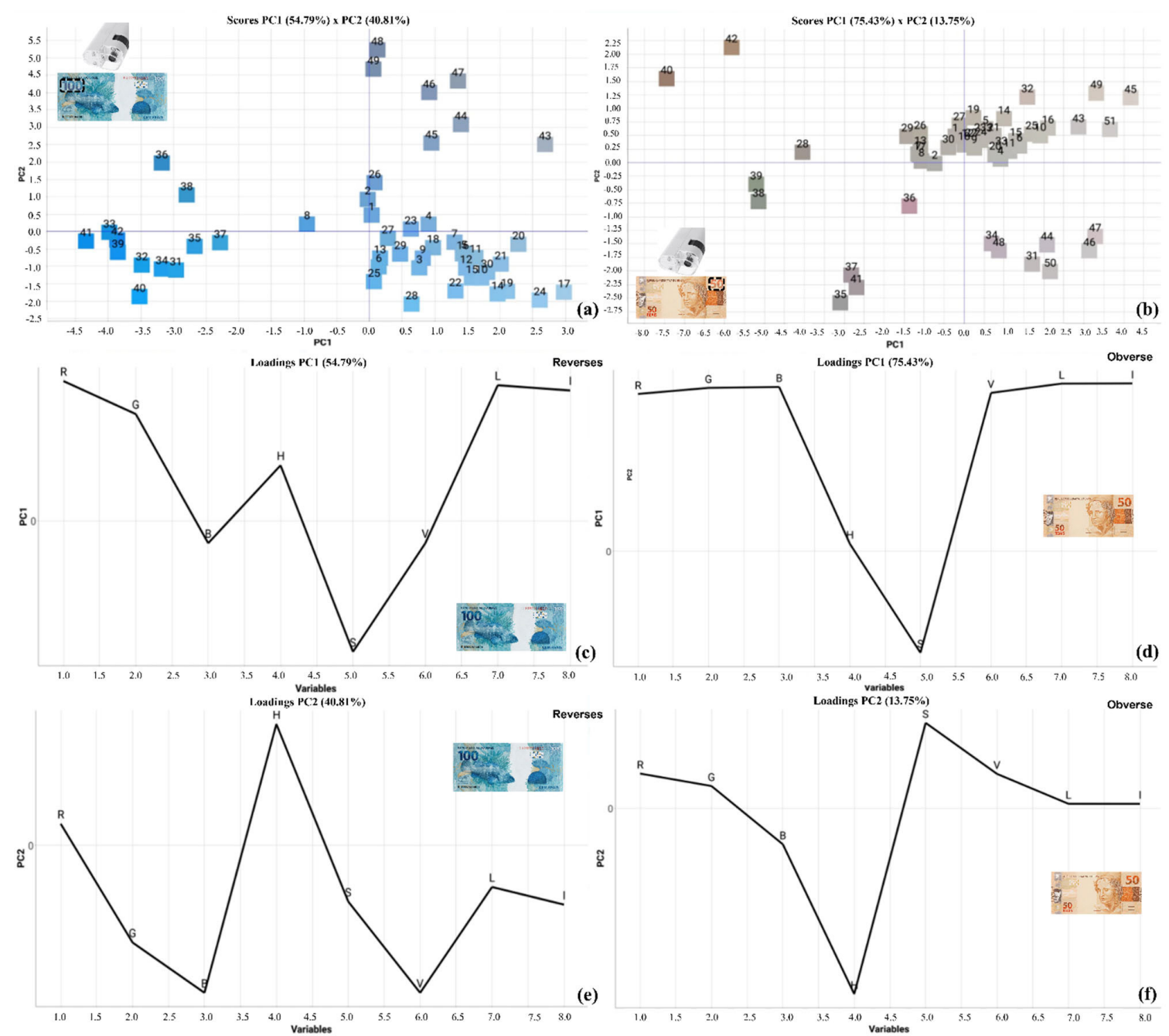

Figure 5. PCA analysis (scores (a-b) and loadings (c-f) plots of PC1 $\times$ PC2) of $\mathrm{R} \$ 100$ banknotes and $\mathrm{R} \$ 50$ banknotes using a microscope (120x) and a Samsung S7 smartphone allied to PhotoMetrix ${ }^{\circledR}$ in the following regions: (a) the microprinting left number and (b) the top number. Loadings plots of PC1 and PC2 correspond to reverse (c,e) and obverse (d.f) regions. 
application allied to PCA. Twelve Real banknotes (four each of $\mathrm{R} \$ 20, \mathrm{R} \$ 50$ and $\mathrm{R} \$ 100$ ) were used for the study, and four Argentine weight banknotes (\$100) were used. The digital images were obtained with a second-generation Motorola X smartphone (13 MP camera, android 6.0, ROI of $48 \times 48$ pixels and focal length of $12 \mathrm{~cm}$ ). The authors divided the study into two experiments. In the first experiment, they only used Real banknotes $(n=12)$, and in the second, they used the entire dataset $(n=16$; Real plus Argentine weight banknotes); using only three PCs, they were able to describe $98.5 \%$ of the total variance for the Real banknote and $98.75 \%$ of the total variance comparing the Real banknotes to the Argentine weight banknotes. ${ }^{23}$ It is important to highlight that the present study presents a sum of explanatory variables using only 2 PCs: $99.35 \%$ (obverse) and $98.55 \%$ (reverse) for R $\$ 100$, and $99.75 \%$ (obverse) and $99.62 \%$ (reverse) for $\mathrm{R} \$ 50$. Although this study is more complex since it groups the banknotes (authentic and counterfeit) of the same value, it demonstrates that using the universal microscope accessory coupled to Photometrix ${ }^{\circledR}$ (widespread application in the scientific middle) $)^{24-34}$ provide greater confidence and robustness to the classification of banknotes.

Vittorazzi et al. ${ }^{22}$ presented a study using the PhotoMetrix ${ }^{\circledR}$ application to classify Real banknotes through digital images for the $R \$ 20, R \$ 50$ and $R \$ 100$ denominations. An optimization test was performed to determine the best parameters for classifying the images; the best region was the microimpression in the effigy and around the animal, which were acquired at $16 \times 16$ pixels, with a focal length of $10 \mathrm{~cm}$ and with controlled ambient luminosity. Notably, the optimization tests were carried out for the $\mathrm{R} \$ 50$ banknote and subsequently applied to the other banknotes. In addition to these parameters, variation in the smartphone model (Motorola G5 Plus, Samsung S7 and LG K10) was also evaluated, and the Motorola G5 Plus produced better results. After the optimization tests, the authors evaluated samples of counterfeit banknotes seized by the Forensic Police of Espírito Santo state, Brazil. The results were promising since luminosity was not a determining factor. Explanatory variances were obtained from 97.2 to $98.64 ; 89.75$ to 96.15 and 72.5 to $86.37 \%$, respectively, for $\mathrm{R} \$ 100, \mathrm{R} \$ 50$ and $\mathrm{R} \$ 20$ banknotes. Importantly, the results obtained with the microscope coupled to a smartphone had lower variation between the PCs since the images were better quality, allowing for obtaining a greater amount of discriminatory information discriminatory for constructing the PCA model.

When evaluating the PCA for NDL data (Figure 6), the same experimental conditions were adopted, but regions a, $\mathrm{b}, \mathrm{c}, \mathrm{e}, \mathrm{f}$ and $\mathrm{h}$ were used; these regions corresponded to the region of the coat of arms of the republic in calcography, the state map with calcography, the acronym optical variation ink, negative guilloche with imaging, typographic numbering and the region with line printing. Using the PCA score graphs, Figure S4, SI section, shows that the best region to evaluate the authenticity of the NDL is the state map with calcography and microprints. These regions have great potential for assessing NDLs considering each region in isolation, since the grouping in the $\mathrm{PC} 1$ and $\mathrm{PC} 2$ space was better defined compared to the other regions.

In the score plot (Figure 6a), each component was different between samples; PC1 shows that the main variation in the data set is equivalent to the differences between the authentic and the counterfeit NDL and PC2 in the dispersion between the falsified NDLs. The loadings plot (Figures $6 \mathrm{~b}$ and $6 \mathrm{c}$ ) demonstrates that the $\mathrm{H}$ and $\mathrm{S}$

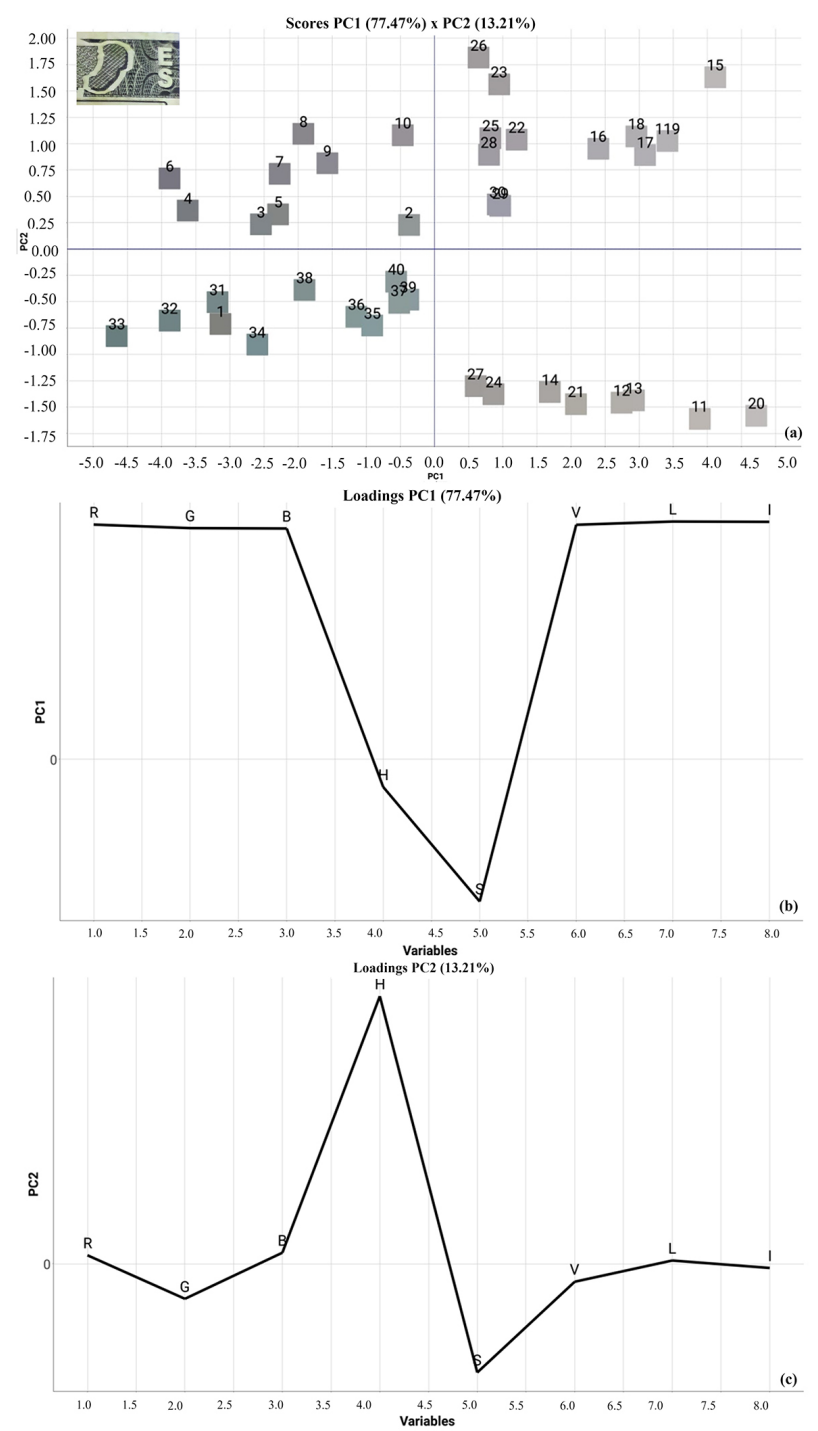

Figure 6. PCA (scores (a) and loadings (b-c) plots of PC1 $\times$ PC2) of a NDL captured with a smartphone microscope $(120 \times)$ associated with a Samsung S7 and the PhotoMetrix ${ }^{\circledR}$ app applied in regions of state map. 
channels are responsible for the differences between the authentic and the counterfeit NDL. On other hand, the $\mathrm{H}$ channel (hue) mainly influences this differentiation when the loadings of PC1 and PC2 are evaluated simultaneously. The NDL analysis showed a total variance of $90.63 \%$ considering the two PCs. A trend toward similarity between the counterfeit samples was observed in the dendrogram for region $b$, while the authentic samples were a more compact group, which strengthened the PCA.

\section{Conclusions}

This study proposed using digital images obtained with a universal microscope for a smartphone for differentiating Brazilian banknotes and 40 samples of NDLs $(n=10$ authentic and $n=30$ simulated). A total of 51 samples ( $n=30$ authentic and $n=21$ counterfeit) were collected. First, only the use of digital images was evaluated visually to verify the authenticity of both types of documents. The region of the holographic band presented in metallized parts had excellent ability to discriminate the authenticity from visualizing the letters of the Real and the value of the banknotes. The surroundings of the animal also had microprints in the value corresponding to each banknote. For NDLs, it was clearly possible to identify high-resolution information, such as "SES," "CAR" and trace crossing for authentic documents. In all the regions studied, the application of the microscope coupled to the smartphone camera improved the ability to determine authenticity. These regions ( $\mathrm{R} \$ 100$ reverse number with microprints, $\mathrm{R} \$ 50$ obverse the top number) can be considered specific regions for application in document analysis. Thus, the microscope coupled to the smartphone together with PhotoMetrix is as a fast, inexpensive, reliable and portable analytical tool that does not require a sample preparation step and can be applied to routine forensic analysis.

\section{Supplementary Information}

Supplementary data are available free of charge at http://jbcs.sbq.org.br as PDF file.

\section{Acknowledgments}

The authors thank FAPES (EDITAL FAPES/CNPq No. 13/2018-PICJr-termo de outorga: 480/2108), CAPES (23038.007083/2014-40) and CNPq (422555/2018-5, and $305359 / 2017-7$ ) for financial support. The authors would also like to thank the Núcleo de Competências em Química do Petróleo and LabPetro for the use of their facilities and Polícia Civil do Espírito Santo for providing the samples.

\section{Author Contributions}

Rayana A. Costa was responsible for conceptualization, methodology, investigation, visualization and writing the original draft; Bruno V. Vittorazzi for investigation and methodology; Amanda P. Barbosa for investigation and methodology; Victória B. da Rocha for investigation and methodology; Jandira M. O. B. Brandão for investigation and acquisition of seized banknotes; Valdemar Lacerda Jr. for editing and project administration and supervision; Paulo R. Filgueiras for final review of the writing and editing, visualization and validation; Wanderson Romão for formal analysis funding acquisition, final review of the writing, editing and project administration and supervision.

\section{References}

1. Correia, R. M.; Domingos, E.; Tosato, F.; Aquino, L. F. M.; Fontes, A. M.; Cáo, V. M.; Filguieras, P. R.; Romão, W.; Forensic Chem. 2018, 8, 57.

2. Brandão, J. M. O. B.; Almeida, N. S. M.; Dixini, P. V. M.; Baier, C. H. A.; Dias, H. P.; Bassane, J. F. P.; França, H. S.; Silva, S. R. C.; Aquije, G. M. F. V.; Romão, W.; Anal. Methods 2016, 8, 771.

3. Eberlin, L. S.; Haddad, R.; Neto, R. C. S.; Cosso, R. G.; Maia, D. R. J.; Maldaner, A. O.; Zacca, J. J.; Sanvido, G. B.; Romão, W.; Vaz, B. G.; Ifa, D. R.; Dill, A.; Cooks, R. G.; Eberlin, M. N.; Analyst 2010, 135, 2533.

4. Bruni, A. T.; Velho, J. A.; de Oliveira, M. F.; Fundamentos de Química Forense, $1^{\text {st }}$ ed.; Millennium: Campinas, Brazil, 2012.

5. Romão, W.; Schwab, N. V.; Bueno, M. I. M. S.; Sparrapan, R.; Eberlin, M. N.; Martyni, A.; Sabino, B. D.; Maldaner, A. O.; Quim. Nova 2011, 34, 1717.

6. Banco Central do Brasil, Estatística de Falsificação - 2019, https://www.bcb.gov.br/content/estatisticas/mecirestfalsas/ EstatisticaFalsificacao\%20-\%20UF\%20X\%20Denominacao_ internet_2019.pdf, accessed in November 2021.

7. Banco Central do Brasil, Estatística de Falsificação - 2020, https://www.bcb.gov.br/content/estatisticas/mecirestfalsas/ EstatisticaFalsificacao\%20-\%20UF\%20X\%20Denominacao_ internet_2020.pdf, accessed in November 2021.

8. Segunda Família do Real - Cartilha de Treinamento, https:// www.bcb.gov.br/novasnotas/assets/downloads/materialapoio/2e5/Cartilha.pdf, accessed in November 2021.

9. de Almeida, M. R.; Correa, D. N.; Rocha, W. F. C.; Scafi, F. J. O.; Poppi, R. J.; Microchem J. 2013, 109, 170.

10. Rodrigues, A. R. N.; Melquiades, F. L.; Appoloni, C. R.; Marques, E. N.; Forensic Sci. Int. 2019, 302, 109872.

11. Weyermann, C.; Marquis, R.; Mazzella, W.; Spengler, B.; J. Forensic Sci. 2007, 52, 216.

12. Jara, M. A. Z.; Obregón, C. L.; del Castillo, C. A.; Appl. Radiat. Isot. 2018, 135, 212. 
13. Szafarska, M.; Wietecha-Posłuszny, R.; Wouniakiewicz, M.; Koscielniak, P.; Forensic Sci. Int. 2011, 212, 78.

14. Schmidt, E. M.; Franco, M. F.; Regino, K. G.; Lehmann, E. L.; Arruda, M. A. Z.; Rocha, W. F. C.; Borges, R.; de Souza, W.; Eberlin, M. N.; Correa, D. N.; Sci. Justice 2014, 54, 459.

15. Domingos, E.; de Carvalho, T. C.; Pereira, I.; Vasconcelos, G. A.; Thompson, C. J.; Augusti, R.; Rodrigues, R. R. T.; Tose, L.; Santos, H.; Araujo, J. R.; Vaz, B. G.; Romão, W.; Anal. Methods 2017, 9, 4400 .

16. Almeida, C. M.; Sales, D. D.; Tosato, F.; dos Santos, N. A.; Allochio Filho, J. F.; Macrino, C. J.; Pinto, F. E.; Filgueiras, P. R.; Romão, W.; Microchem. J. 2019, 148, 220.

17. Oliveira, V. S.; Honorato, R. S.; Honorato, F. A.; Pereira, C. F.; Forensic Sci. Int. 2018, 286, 121.

18. Ren, G.; Zhu, Z.; Zhang, J.; Li, Y.; Han, J.; Opt. Commun. 2020 , 475, 126267.

19. Damasceno, D.; Toledo, T. G.; Godinho, M. S.; da Silva, C. P.; de Oliveira, S. B.; de Oliveira, A. E.; Quim. Nova 2015, 38, 836.

20. Oliveira, L. F.; Canevari, N. T.; Jesus, A. M. D.; Pereira-Filho, E. R.; Rev. Virtual Quim. 2013, 5, 169.

21. Benedetti, L. P. S.; dos Santos, V. B.; Silva, T. A.; BenedettiFilho, E.; Martins, V. L.; Fatibello-Filho, O.; Anal. Methods 2015, 7, 7568 .

22. Vittorazzi, B. V.; Costa, R. A.; Coelho, L. M.; Isidoro, M. M.; Lima, K. M. G.; Filgueiras, P. R.; Romão, W.; Quim. Nova 2020, $43,447$.

23. Helfer, G. A.; Magnus, V. S.; Bock, F. C.; Teichmann, A.; Ferrão, M. F.; da Costa, A. B.; J. Braz. Chem. Soc. 2017, 28, 328.
24. de Oliveira, P. A. C.: Medidas Colorimétricas com Smartphone para Identificação de Amostras de Cocaína e Quantificação de Alguns Adulterantes; MSc Dissertation, University of Brasília, Brasília, Brazil, 2017, available at https://repositorio.unb.br/ handle/10482/25272, accessed in November 2021.

25. Soares, S.; Lima, M. J. A.; Rocha, F. R. P.; Microchem. J. 2017, 133, 195.

26. Bock, F. C.; Helfer, G. A.; da Costa, A. B.; Dessuy, M. B.; Ferrão, M. F.; Food Anal. Methods 2018, 11, 1951.

27. Helfer, G. A.; Tischer, B.; Filoda, P. F.; Parckert, A. B.; dos Santos, R. B.; Vinciguerra, L. L.; Ferrão, M. F.; Barin, J. S.; da Costa, A. B.; Food Anal. Methods 2018, 11, 2022.

28. Dionizio, B. S.; Babos, D. V.; da Souza, D. H. F.; Pereira-Filho, E. R.; BrJAC-Braz. J. Anal. Chem. 2019, 6, 38.

29. Lumbaque, E. C.; da Silva, B. A.; Bock, F. C.; Helfer, G. A.; Ferrão, M. F.; Sirtori, C.; J. Hazard. Mater. 2019, 378, 120740.

30. Soares, S.; Torres, K. G.; Pimentel, E. L.; Martelli, P. B.; Rocha, F. R. P.; Talanta 2019, 195, 229.

31. Costa, V.; Neiva, A.; Pereira-Filho, E.; Ecletica Quim. J. 2019, $44,62$.

32. Soares, S.; Nunes, L. C.; Melchert, W. R.; Rocha, F. R. P.; Microchem J. 2020, 152, 104273.

33. Mohan, P. J.; Gupta, S. D.; Photosynthetica 2019, 57, 388.

34. Pappis, C.; Librelotto, M.; Baumann, L.; Parckert, A. B.; Santos, R. O.; Teixeira, I. D.; Helfer, G. A.; Lobo, E. A.; da Costa, A. B.; BrJAC-Braz. J. Anal. Chem. 2019, 6, 58.

Submitted: June 14, 2021 Published online: November 30, 2021 